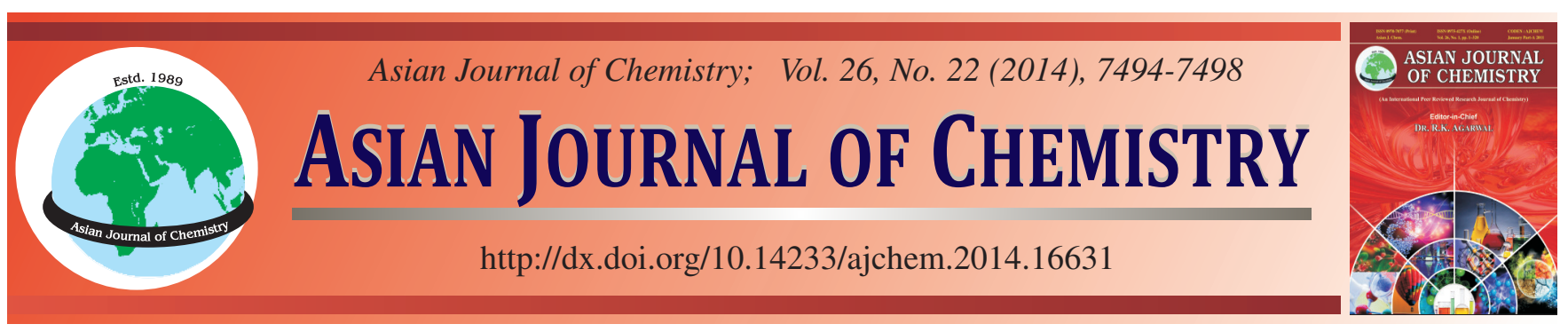

\title{
Determination of Dopamine, Glycine, Tryptohan, Valine, Leucine and Isoleucine Using 4-Dimethylaminobenzaldehyde by HPLC in Pharmaceutical Samples
}

\author{
IndRa PANJWANI ${ }^{*}$, G.M. Arain and M.Y. KhUHAWAR
}

Institute of Advanced Research Studies in Chemical Sciences Jamshoro, University of Sindh, Jamshoro, Sindh, Pakistan

*Corresponding author: E-mail: icpanjwani@yahoo.com

\begin{abstract}
A simple isocratic HPLC procedure has been developed for simultaneous separation and quantitation of dopamine, glycine, tryptophan, valine, leucine and isolucine by pre-column derivatization with 4-dimethylaminobenzaldehyde and UV detection at $240 \mathrm{~nm}$. The derivatives formed were examined spectrophotomatrically for the effects of $\mathrm{pH}$, derivatizing reagent concentration and heating time in aqueousmethanolic solution. The analytes and excess of the derivatizing reagent separated completely from the column Kromasil $100 \mathrm{C}-185 \mu \mathrm{m}$, $(250 \times 0.46 \mathrm{~cm})$ when eluted with methanol-water-potassium chloride $(1 \mathrm{M})$ adjusted to $\mathrm{pH} 2(55: 44.75: 0.25 \mathrm{v} / \mathrm{v} / \mathrm{v})$ with a flow rate of 0.4 $\mathrm{mL} \mathrm{min}^{-1}$. Linear calibration were obtained with $2-400 \mu \mathrm{g} \mathrm{mL}{ }^{-1}$ and limits of detection within 13.2-533.2 $\mathrm{ng} / 20 \mu \mathrm{L}$. A number of amino acids and pharmaceutical additives did not interfere to the determination. The derivatization, separation and quantitation was repeatable with RSD within $4.5(n=6)$. The method was used for determination of dopamine, tryptophan, valine, leucine and isoleucine from pharmaceutical preparation. The results were further supported by standard addition method. The recovery from pharmaceutical preparation of dopamine was $96.8 \%$, tryptophan $99.6 \%$, valine $98.7 \%$, leucine $98.8 \%$ and isoleucine $99.3 \%$ with RSD $(n=3) 3.4,3.1,1.3,3.8$ and $1.8 \%$, respectively. The results were further supported by standard addition method.
\end{abstract}

Keywords: HPLC, Determination, Dopamine, tryptophan, Valine, leucine, Isoleucine, Derivatization, 4-Dimethylaminobenzaldehyde.

\section{INTRODUCTION}

Dopamine and tryptophan are currently the subject of intense research focus by chemists and neuroscientists. Therefore, it is of great significance to develop simple and rapid determination methods of dopamine and tryptophan. Dopamine (DA) is a monoamine neurotransmitter distributed in the central neural system, brain tissues and body fluids of mammals. It plays pivotal roles in the function of central nervous, renal, hormonal and cardiovascular system. Abnormal concentration levels of dopamine may lead to several diseases. Detection and quantification of dopamine is important in diagnoses, monitoring, prevention and treatments of some certain diseases, such as Parkinson's, Alzheimer's disease, Huntington's, epilepsy, pheochromocytoma, neuroblastoma and HIV infection ${ }^{1-4}$. Glycine is inhibitory amino acid ${ }^{5}$ and act mainly in the spinal cord and in the brain system via the strychnine-sensitive glycine receptor. Glycine also exhibits a key role in the excitatory neuro-transminion in the $\mathrm{N}$-methyl -D-aspartate receptor complex $^{6,7}$. The amino acids L-tryptophan (Trp) is essential for protein synthesis and is a precursor of a large number of biologically active metabolites, including the cerebral indolylamine serotonin ${ }^{8}$. Valine may be helpful in building muscle and in repairing tissue damage from liver and gallbladder disease. Leucine is essential for growth as a stimulator for protein synthesis in muscle. Leucine is helpful in healing wounds and injuries and helps balance blood sugar because it produces energy. Leucine may be a key regulatory amino acid for maintenance of muscle mass during catabolic periods such as weight $\operatorname{loss}^{9}$. Isoleucine can help reduce the harmful effects of stress on body and isoleucine contributes to the biochemical process that gives energy and helps to build lean muscle mass and reduces fat. Valine, leucine and isoleucine are branchedchain amino acids (BCAA) that help in wound healing. Valine specifically supports lean muscle-mass building and muscle repair $^{10}$.

The amino acids do not indicate fluorescence or strong absorbance in ultraviolet/visible region, thus derivatization is generally carried out to improve both selectivity and sensitivity. The analytical procedure for the determination of these compounds are mostly based on high performance liquid chromatography (HPLC) with fluoresence or electrochemical detection ${ }^{11-20}$, Gas chromatography with flame ionization or mass spectroscopic detection ${ }^{21-23}$, Capillary electrophoresis with UV or laser-induced fluorescence detection ${ }^{24-28}$, spectrophotometry ${ }^{29}$, polarography $^{30}$ and flow injection analysis ${ }^{31}$. Among these 
methods HPLC is more frequently reported using pre or postcolumn derivatizing reagents ${ }^{32}$. Some of the commonly used derivatizing reagents for amine and amino acids are ninhydrin ${ }^{33}$, $O$-pathalaldehyde ${ }^{34}$, phenyl isocynate ${ }^{35}$, densyl chloride ${ }^{36,37}, 9$ fluroenyl methyl chloroformate ${ }^{38}$ and 6-amino-quinolyl-Nhydroxysuccinimidyl carbamate ${ }^{39}$. However a number of difficulties associated with HPLC procedure have been reported ${ }^{40}$.

The development of new reagents for the HPLC determination of biological active amine and amino acids could be of value. 4-Dimetylaminobenzaldehyde (DAB) has been used as derivatizing reagent for the spectrophotometric determination of hydrazine ${ }^{41}$, Lamivudine $^{42}$, bopindolol ${ }^{43}$, GC determination of dimethylhydrazine ${ }^{44}$ and HPLC determination of phenylpropanolamine (PPA) ${ }^{45}$. The present work examines 4-dimethylaminobenzaldehyde as derivatizing reagent for HPLC separation and quantitation of dopamine, glycine, tryptophan, valine, leucine and isoleucine and determination of dopamine, tryptophan, valine, leucine and isoleucine from pharmaceutical preparation. The experimental conditions are optimized for derivatization and HPLC separation. Linearity, limit of detection (LOD), limit of quantitation (LOQ) and repeatability of quantitation are examined.

\section{EXPERIMENTAL}

Reagent grade chemicals: Tryptophan, threonine, creatinine sulfate, tyramine, methanol (E. Merck, Germany) and acetonitrile (Fluka Switzerland) were used. Glycine, serine, leucine, valine, (E. Merck Germany), phenylalanine, histadine, histamine, methionine, tyrosine, lysine, isoleucine (Fluka Switzerland) were used. Sodium acetate, acetic acid, sodium bicarbonate, sodium carbonate, boric acid, borax, ammonium chloride, ammonia (23\%), hydrochloric acid (37\%) (E. Merck Germany) were used. Freshly prepared doubly distilled water was used for HPLC studies and for the preparation of solution.

The buffer solutions in the $\mathrm{pH}$ range $1-10$ at 0.5 and unit interval were prepared from potassium chloride (1M) pH adjusted to 1-2 with hydrochloric acid (0.1M), sodium acetate (1M)-acetic acid (1M) pH 3-6, ammonium acetate (1M) pH 7, sodium tetraborate $(1 \mathrm{M})$ - boric acid $(1 \mathrm{M}) \mathrm{pH} 8-9$, sodium carbonate (saturated) and sodium bicarbonate $(1 \mathrm{M}) \mathrm{pH} 9$ and ammonium chloride (1M)-ammonia solution (1M) pH 10.

$\mathrm{pH}$ Measurement was made with Orion 420A pH meter (Orion (pvt) Ltd, Boston, MA, USA) with glass electrode and internal reference electrode. A Hitachi 655A liquid chromatograph (Hitachi (pvt) Ltd, Tokyo, Japan) connected with variable wavelength UV monitor and Rheodyne 7125 injector was used. The UV detector was connected with computer with CSW-32 (Data Apex Ltd (C) 2001www.dataapex.com) software. A Kromasil $100 \mathrm{C}-185 \mu \mathrm{m},(250 \times 0.46 \mathrm{~cm})$ was used through out the study. The spectrophotometric studies were carried out on double beam Hitachi 220 spectrophotometer (Hitachi (pvt) Ltd, Tokyo, Japan) with dual $1 \mathrm{~cm}$ path length quartz cuvettes. Dopamine Injection (Howards Chemical and Pharmaceutical Works (Pvt) Ltd, Lahore), Tablets aminess N [Medisure laboratories (MDS) Medisure Laboratorie Pakistan (Pvt) Karachi] were purchased from local market Hyderabad and Tablet Amino 75 SOLGAR (U.K) were purchased from London, U.K.
Spectrophotometric procedure: Solution (0.1-1.0 mL) containing 50-5000 $\mu \mathrm{g} / \mathrm{mL}$ dopamine, glycine, tryptophan, valine, leucine and isolucine separately was transferred to 10 $\mathrm{mL}$ volumetric flask, added $1 \mathrm{~mL}$ sodium acetate buffer $\mathrm{pH} 5$ and $2 \mathrm{~mL}$ reagent 4 -dimethylaminobenzaldehyde $(1 \% \mathrm{w} / \mathrm{v}$ in methanol). The mixture was heated on water bath at $80{ }^{\circ} \mathrm{C}$ for $15 \mathrm{~min}$ and the solution after cooling at room temperature was adjusted to the mark with methanol. The solution was mixed well and absorbance was measured against reagent blank at $404 \mathrm{~nm}$.

HPLC procedure: Solution (0.1-1.0 mL) containing 25$4000 \mu \mathrm{g} / \mathrm{mL}$ dopamine, glycine, tryptophan, valine, leucine and isoleucine was transferred to $10 \mathrm{~mL}$ volumetric flask, added $1 \mathrm{~mL}$ of sodium acetate buffer $\mathrm{pH} 5,2 \mathrm{~mL}$ reagent 4dimethylaminobenzaldehyde ( $1 \% \mathrm{w} / \mathrm{v}$ in methanol) and heated on water bath for $15 \mathrm{~min}$ at $80{ }^{\circ} \mathrm{C}$. The solution was cooled at room temperature and volume was adjusted upto the mark with methanol. The contents were mixed well and $20 \mu \mathrm{L}$ was injected on the column Kromasil 100 C-18 $5 \mu \mathrm{m},(250 \times 0.46$ $\mathrm{cm})$ and derivatives eluted with methanol-water-KCl $(1 \mathrm{M})$ adjusted to $\mathrm{pH} 2$ (55: 44.75: $0.25 \mathrm{v} / \mathrm{v} / \mathrm{v})$ with a flow rate of 0.4 $\mathrm{mL} / \mathrm{min}$ and UV detection was at $240 \mathrm{~nm}$.

Analysis of dopamine from pharmaceutical preparation: The solution $1 \mathrm{~mL}$ of dopamine injection contaning 200 $\mathrm{mg} / 5 \mathrm{~mL}$ (Howards Chemical and Pharmaceutical Works (Pvt) Ltd, Lahore) was diluted in deionized water and volume adjusted upto $100 \mathrm{~mL}$. Three solutions of $0.5 \mathrm{~mL}$ each were transferred to $10 \mathrm{~mL}$ volumetric flasks and HPLC procedure was followed. The quantitation was made from external calibration curve prepared from standard solutions using linear regression equation $\mathrm{Y}=\mathrm{ax}+\mathrm{b}$.

Analysis of dopamine from pharmaceutical preparation by standard addition: A dopamine injection was processed as above procedure. Three solutions of $0.5 \mathrm{~mL}$ each were transferred to $10 \mathrm{~mL}$ volumetric flasks and two solution were added $1 \mathrm{~mL}$ of standard solution containing 30 or $50 \mu \mathrm{g} \mathrm{mL}^{-1}$, respectively of dopamine. All the solutions were processed as HPLC procedure. The quantitation was made from linear calibration and from the average increase in response $(n=5)$ with added standards.

Analysis of tryptophan, valine, leucine and isoleucine from pharmaceutical preparation: Five Aminess $\mathrm{N}$ tablets (MDS) Medisure Laboratorie Pakistan (Pvt) Karachi and Amino 75 capsule SOLGA (U.K) were crushed to fine powder and well mixed. Powder 0.84 and $0.7947 \mathrm{~g}$ corresponding to one tablet and one capsule respectively were dissolved in $10 \mathrm{~mL}$ of deionized water. The solution was filtered and final volume was adjusted to $25 \mathrm{~mL}$. The solution $0.8 \mathrm{~mL}$ from each was transferred to $10 \mathrm{~mL}$ volumetric flasks and HPLC procedure was followed. The quantitation was made from external calibration curve prepared from standard solutions.

Analysis of tryptophane, valine, leucine and isoleucine from pharmaceutical preparation by standard addition: Five aminess $\mathrm{N}$ tablets and amino 75 capsule were processed and their aqueous solutions were prepared as above procedure. Two solutions of $0.4 \mathrm{~mL}$ each from both the solutions were transferred to $10 \mathrm{~mL}$ volumetric flasks and standard solutions of tryptophan, valine, leucine and isoleucine standards corres- 
ponding to $25,200,100$ and $200 \mu \mathrm{g} \mathrm{mL}^{-1}$ at final concentrations were added. All solutions were processed as HPLC procedure. The quantitation was made from linear calibration and from the average increase in response $(n=5)$ with added standards.

\section{RESULTS AND DISCUSSION}

Determination of biological active amines and amino acid from pharmaceutical preparations continues to attract the attention of analytical chemists. A number of different derivatizing reagents are reported for their determination using UV or fluorimetric detection ${ }^{33-39}$. The procedures are based on the determination of a number of amines and amino acids simultaneously or the determination of a limited number of the analytes from specific matrix. The work examines separation and quantitation of 5 analytes. The reagent 4-dimethylaminobenzaldehyde is reported to react with primary amino group containing compound to form Schiff bases ${ }^{41-45}$.

The reaction of dopamine, glycine, tryptophan, valine, leucine and isoleucine with 4-dimethylaminobenzaldehyde were examined in aqueous methanolic solution (Fig. 1). The reactions initially were monitored spectrophotometrically at $404 \mathrm{~nm}$ to optimize the reaction condition. The conditions, which gave maximum responses (Absorbance at particular wave length) was considered as optimal. The $\mathrm{pH}$ was varied within the range 1-10 at unit interval. The optimum responses were obtained within $\mathrm{pH} 5-6$ with maximum at $\mathrm{pH} 5$ and acetate buffer was selected (Fig. 2). Heating time at $80^{\circ} \mathrm{C}$ was varied from 2.5-20 min with an interval of $5 \mathrm{~min}$. The maximum response was measured by heating dopamine, glycine, tryptophan, valine, leucine and isoleucine for $10 \mathrm{~min}$, thus was fixed. The amount of derivatizing reagent 4-dimethylaminobenzaldehyde was varied between 1-4 mL at an interval of $1 \mathrm{~mL}$ at a concentration of $1 \%$ (w/v in methanol) and optimal response was obtained with $2 \mathrm{~mL}$. The derivatives once formed were highly stable and did not show any change in absorbance up to $24 \mathrm{~h}$.

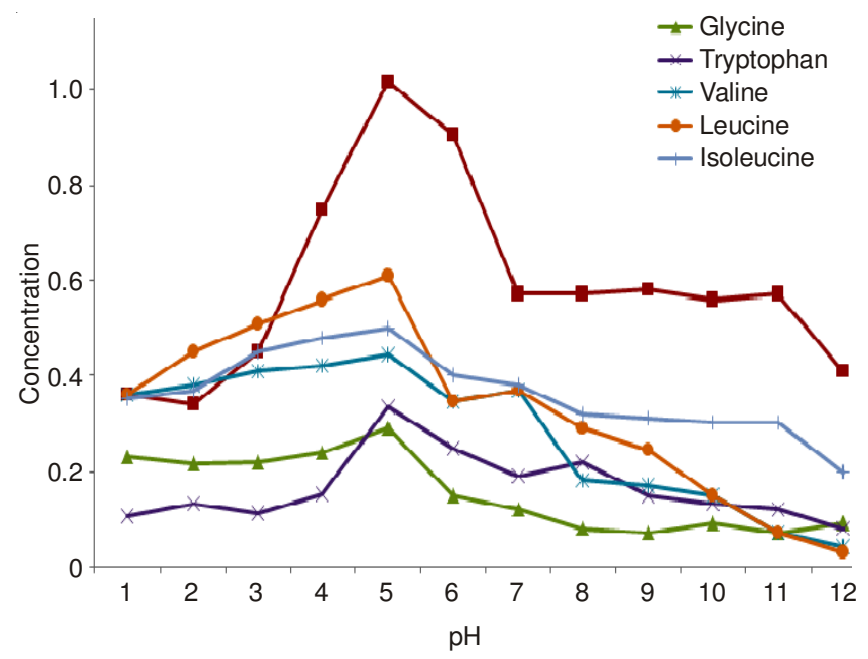

Fig. 2. Effect of pH on the absorbance of 4-dimethylaminobenzaldehyde derivatives

Tryptophan and dopamine with 4-dimethylaminobenzaldehyde indicated molar absorpitivity $2.5 \times 10^{3}$ and $1.98 \times 10^{3}$ $\mathrm{L} \mathrm{mol}^{-1} \mathrm{~cm}^{-1}$ and obeyed Lambert-Beer's law with 5-100 and $5-50 \mu \mathrm{g} \mathrm{mL}^{-1}$ with coefficient of determination $\left(\mathrm{r}^{2}\right) 0.9987$ and 0.997 , respectively. To increase the selectivity of the determination at optimized spectrophotometric conditions HPLC was investigated. Dopamine and tryptophan derivatives of 4-dimethylaminobenzaldehyde eluted from Kromasil $100 \mathrm{C}$ $185 \mu \mathrm{m},(250 \times 0.46 \mathrm{~cm})$ column and separated from the excess of the reagent 4-dimethylaminobenzaldehyde. Dopamine, glycine, tryptophan, valine, leucine, isoleucine also completely separated simultaneously when eluted with mixture of methanol: water: $\mathrm{KCl}$ buffer $(1 \mathrm{M}) \mathrm{pH} 2$ (55: 44.75: 0.25 $\mathrm{v} / \mathrm{v} / \mathrm{v}$ ) with a flow rate of $0.4 \mathrm{~mL} / \mathrm{min}$ and UV detection was at $240 \mathrm{~nm}$ (Fig. 3). The derivative formed were highly stable and the same analytical response was measured even after $12 \mathrm{~h}$ from formation $(n=4)$. Repeatability for the elution of dopamine, tryptophan, valine, leucine and isoleucine derivatives

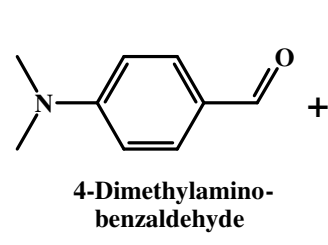<smiles>NCC(=O)O</smiles>

Glycine

(a)

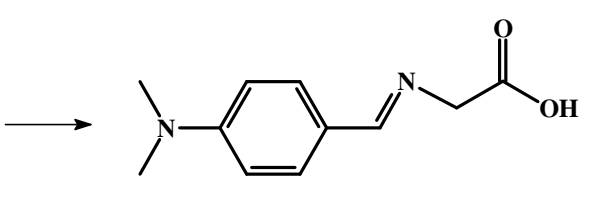

Dimethyl-(4-vinyl-phenyl)-amine) compound with amino-acetic acid

Gly-DAB

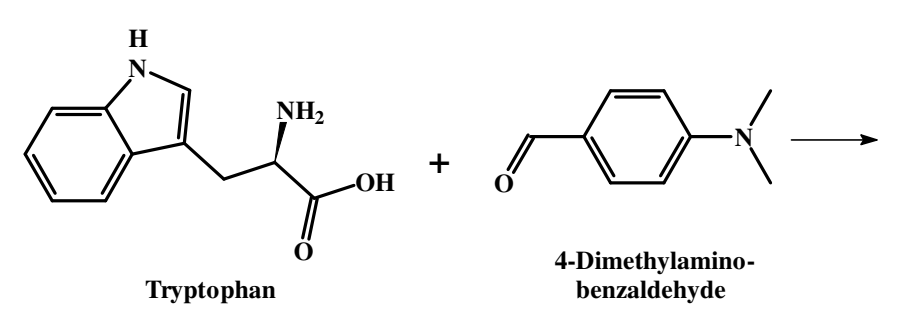

(b)

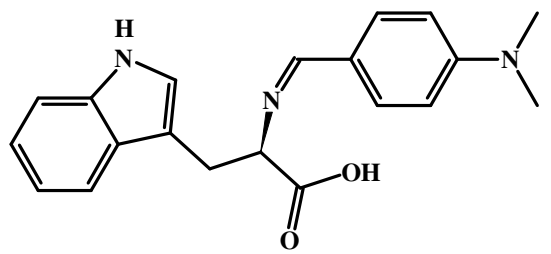

2-Amino-3-(1H-indol-3-yl)propionic acid; compound with dimethyl-(4-vinyl-phenyl)amine

Tryp-DAB

Fig. 1. Chemical reactions of 4-dimethylaminobenzaldehyde with (a) glycine (GLY-DAB) (b) tryptophan (TRY-DAB) 


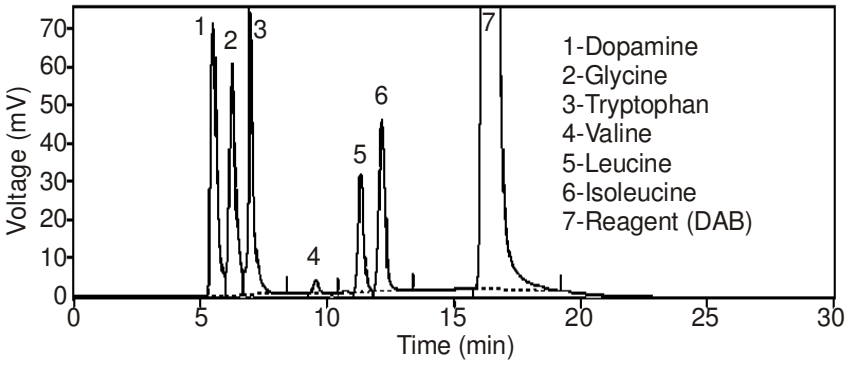

Fig. 3. HPLC separation of derivatives of 4-dimethylaminobenzaldehyde (DAB), (1) dopamine, (2) glycine, (3) tryptophan, (4) valine (5) leucine (6) isoleucine (7) DAB. Column kromasil $100 \mathrm{C}-185 \mu \mathrm{m}$, $(250 \times 0.46)$, eluant Methanol : Water : $\mathrm{KCl}$ buffer $(1 \mathrm{M})(\mathrm{pH} 2)(55$ : $44.75: 0.25: \mathrm{v} / \mathrm{v} / \mathrm{v} / \mathrm{v}$ )with flow rate of $0.4 \mathrm{~mL} \mathrm{~min}^{-1}$ and UV detection was at $240 \mathrm{~nm}$

in terms of average peak height and retention time $(\mathrm{n}=5)$ were observed with RSD within 2.1-4.5\%.

Linear calibration curves for dopamine, glycine, tryptophan, valine, leucine and isoleucine were obtained with 2-50, 20-200, 2-100, 30-400, 20-200 and 80-400 $\mu_{\mathrm{g} \mathrm{mL}}^{-1}$ with coefficient of determination $\left(\mathrm{r}^{2}\right)$ 0.9993, 0.9991, 0.9996, 0.9993, 0.9996 and 0.9979, respectively. Detection limits were measured as three times back ground noise and were obtained $0.66,6.66,0.66,10,6.66$ and $26.66 \mu \mathrm{g} \mathrm{mL}^{-1}$ corresponding to $13.33,133.3,13.33,200,133.3$ and 533.33 ng injection-1 (20 $\mu \mathrm{L})$ of dopamine, glycine, tryptophan, valine, leucine and isoleucine respectively (Table-1). Limit of quantitation measu- red as signal to noise ratio 10:1 were obtained 2, 20, 2, 30, 20 and $80 \mu \mathrm{g} \mathrm{mL}^{-1}$ for dopamine, glycine, tryptophane, valine, leucine and isoleucine, respectively. The amino acids cystine, methonine, phenylalanine, serine, aspergine, tyramine, cysteine, arginine, aspartic acid, threonine, serotonine and glutamic acid when added at the same concentration did not interfere in the determination of dopamine, tryptophan, valine, leucine and isoleucine. Similarly pharmaceutical preparations additives methylparabin, propylparabin, gum acacia, manitol, lactose, fructose, glucose, lactose, sodium chloride, sodium lauryl sulphate, methyl hydroxypropyl cellulose, magnesium stearate and stearic acid were added at least twice the concentration of analyte and did not affect the determination of dopamine, glycine, tryptophan, valine, leucine and isoleucine. Five test solutions within the calibration range of dopamine, glycine, tryptophan, valine, leucine and isoleucine were analyzed and relative errors were obtained $\pm 2.3-4.5 \%$.

Dopamine injection containing $200 \mathrm{mg} / 5 \mathrm{~mL}$ was analysed and the results agreed with the labeled value of tablet with $96.85 \%$ recovery and RSD $3.4 \%$ (Table- 2 ). The solution of the dopamine was spiked with standard solutions and corresponding increase in average response $(n=4)$ (peak height/peak area) was obtained without change in the peak shape of the chromatogram. The presence of constituents of injection did not interfere the determination of the analytes. The recovery of dopamine was calculated $97.2 \%$, with RSD $2.9 \%$ from the dopamine injection.

TABLE-1

QUANTITATIVE HPLC DATA OF AMINO-ACIDS USING 4-DIMETHYLAMINOBENZALDE (DAB) AS DERIVATIZING REAGENT

\begin{tabular}{cccccc}
\hline S. No. & Amino acids & $\begin{array}{c}\text { Calibration range } \\
(\mu \mathrm{g} / \mathrm{mL})\end{array}$ & $\begin{array}{c}\text { Limit of detection }(\mathrm{LOD}) \\
(\mathrm{ng} / 20 \mu \mathrm{L})\end{array}$ & $\begin{array}{c}\text { Limit of quantitation } \\
(\mathrm{LOQ})(\mu \mathrm{g} / \mathrm{mL})\end{array}$ & $\mathrm{r}^{2}$ \\
\hline 1 & Dopamine & $2-50$ & 13.33 & 2 & 0.9993 \\
2 & Glycine & $20-200$ & 133.3 & 20 & 0.9991 \\
3 & Tryptophan & $2-100$ & 13.33 & 30 & 0.9996 \\
4 & Valine & $30-400$ & 200 & 20 & 0.9993 \\
5 & Leucine & $20-200$ & 133.3 & 80 & 0.9996 \\
6 & Isoleucine & $80-400$ & 533.33 & & 0.9979 \\
\hline
\end{tabular}

TABLE-2

HPLC ANALYTICAL RESULTS OF AMINO ACIDS AND AMINES FROM PHARMACEUTICAL SAMPLES USING 4-DIMETHYLAMINOBENZALDEHYDE (DAB) AS DERIVATIZING

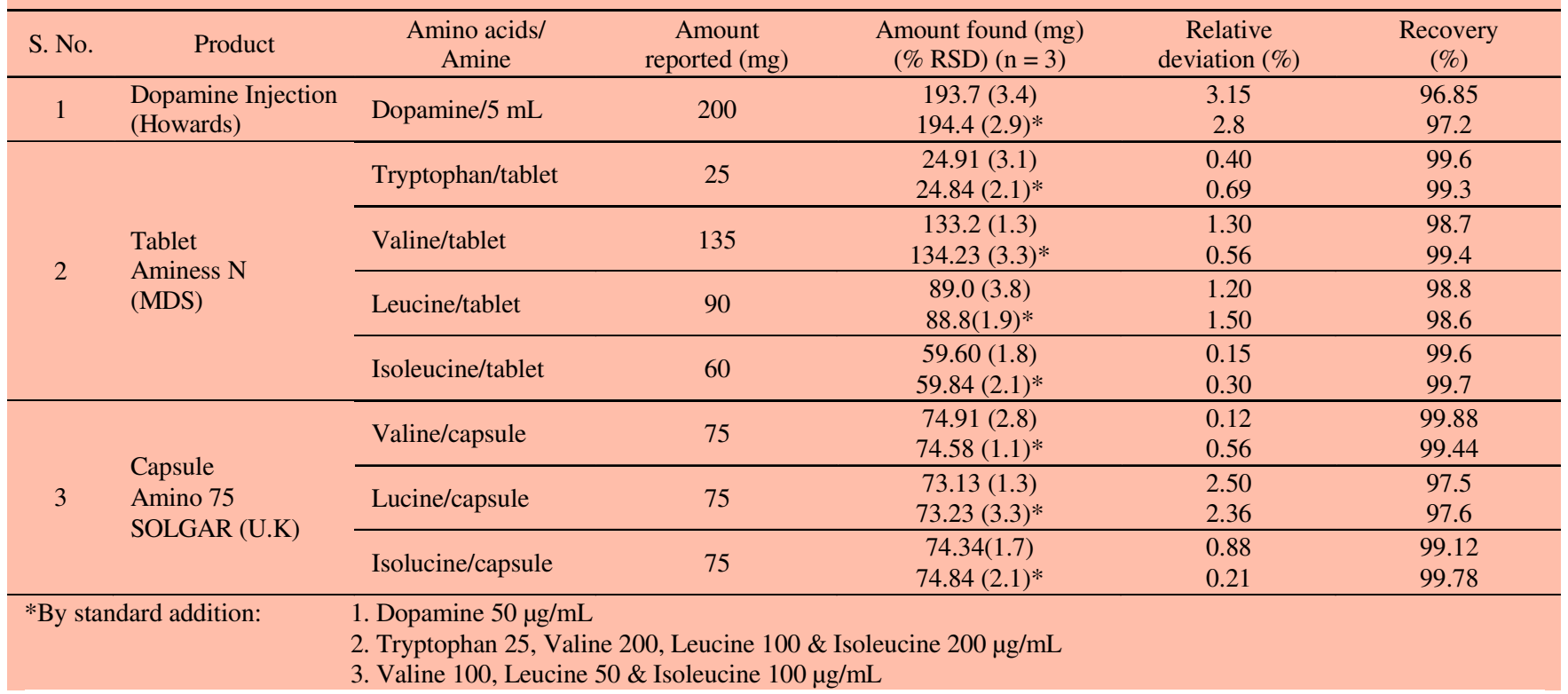


Aminess $\mathrm{N}$ tablets and amino 75 capsules are used as dietary source were analyzed for the contents. Tryptophan, valine, leucine and isoleucine from aminess $\mathrm{N}$ tablets and valine, leucine and isoleucine from amino 75 capsules were determined after extraction of the analytes in water following HPLC analytical procedure. The quantitation was from external calibration. The amounts in aminess $\mathrm{N}$ found were 24.91 , 133.2, 89 and $59.6 \mathrm{mg} /$ tablet with RSD 3.1, 1.3, 3.8 and $1.8 \%$ for tryptophan, valine, leucine and isoleucine respectively (Fig. 4 (a)). Similarly the amount found for amino 75 capsules were 74.91, 73.13 and $74.34 \mathrm{mg} /$ capsule with RSD 2.8, 1.3 and $1.7 \%$ for valine, leucine and isoleucine, respectively. The results agreed with the labeled value of tablet and capsules (Table-2). The solution of aminess $\mathrm{N}$ tablet was spiked with standard solutions of analytes and corresponding increase in average response $(n=4)$ (peak height/peak area) was obtained without change in the peak shape of the chromatogram. The presence of other amino acids and different constituents did not interfere the determination of the analytes (Fig. 4(b)). The recovery of tryptophan, valine, leucine and isoleucine was calculated 99.4, 99.4, 98.7 and $99.7 \%$ with RSD 2.1, 3.3, 1.9 and $2.1 \%$, respectively. Similarly the recovery of valine, leucine and isoleucine from capsule Amino 75 was 99.4, 97.6 and $99.8 \%$ with RSD $1.1,3.3$ and $2.1 \%(\mathrm{n}=3)$, respectively.
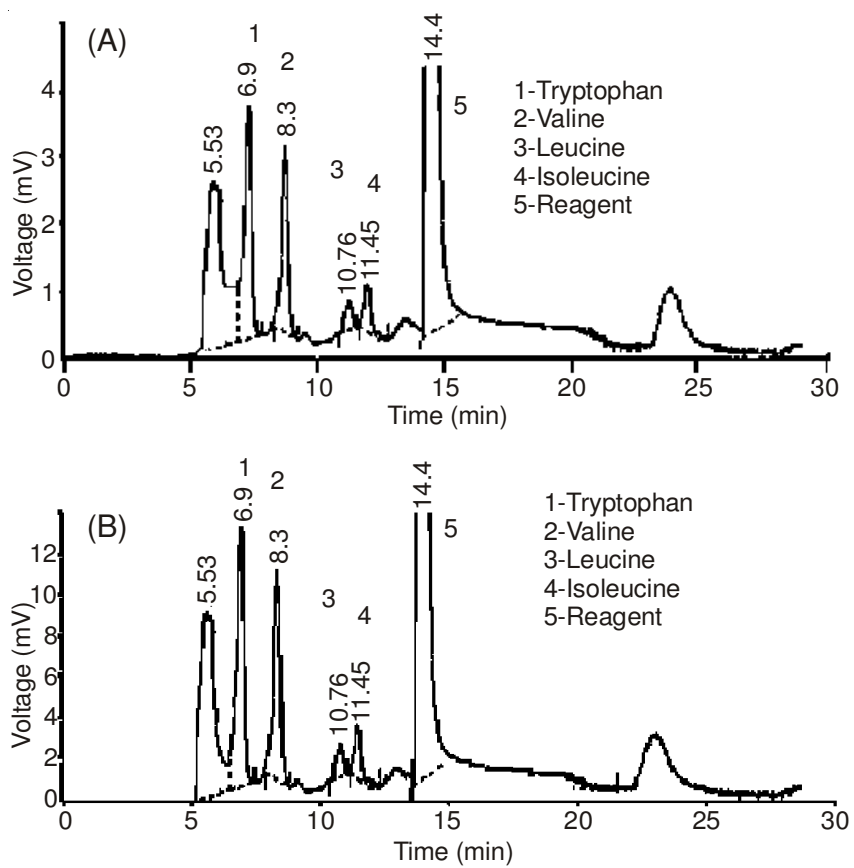

Fig. 4. HPLC response of (A) HPLC response from pharmaceutical samples (B) HPLC response from pharmaceutical samples after spiking with tryptophan 25 , valine 200 , leucine 100 and isoleucine $200 \mu \mathrm{g} / \mathrm{mL}$. Chromatographic conditions as Fig. (b)

\section{Concluson}

An analytical HPLC method has been developed for the selective determination of dopamine, tryptophan, valine, leucine and isoleucine from pharmaceutical preparations using 4-dimethylaminobenzaldehyde as derivatizing reagent. The RDSs of the analysis were obtained within $4.5 \%$. The recovery of the analytes from pharmaceutical preparation calculated by standared addition was within the 96.85-99.8 \% with RSD within 1.1-3.8\%.

\section{REFERENCES}

1. A.H. Liu, I. Honma and H.S. Zhou, Biosens. Bioelectron., 21, 809 (2005).

2. L. Liu, S. Li, L. Liu, D. Deng and N. Xia, Analyst, 137, 3794 (2012).

3. M. Tsunoda, Anal. Bioanal. Chem., 386, 506 (2006).

4. R.M. Wightman, L.J. May and A.C. Michael, Anal. Chem., 60, 769A (1988).

5. G.E. Nilson and P.L. Lutz, Am. J. Physiol., 261, R32 (1991).

6. D.M. Lambert, M. Geurts, G.K. Seriba, J.H. Poupaert and P. Dumont, J. Pharm. Belg., 50, 194 (1995).

7. A. Zinellu, S. Sotgia, E. Pisanu, B. Scanu, M. Sanna, M. Franca Usai, R. Chessa, L. Deiana and C. Carru, Anal. Bioanal. Chem., 398, 1973 (2010).

8. I. Molnár-Perl, Adv. Exp. Med. Biol., 467, 801 (1999).

9. Layman, J. Am. Coll. Nutr., 23(sup6), 631S (2004).

10. C. Hobbs and E. Haas, Building Muscle with Isoleucine, Luecine and Valine; http://www.dummies.com/how-to/content/building-musclewith-isoleucine-luecine-and-valine.html.

11. B.W. Boyd, S.R. Witowski and R.T. Kennedy, Anal. Chem., 72, 865 (2000).

12. D.V. Augusti, F. Carazza, R. Augusti, W.A. Tao and R.G. Cooks, Anal. Chem., 74, 3458 (2002).

13. F.C. Cheng, J.S. Kuo, Y. Shih, J.S. Lai, D.R. Ni and L.G. Chia, J. Chromatogr. A, 615, 225 (1993).

14. E. Sakurai, A. Monura, J. Yamakami and N. Hikichi, J. Pharm. Pharmacol., 48, 911 (1996).

15. R. Kvetnansky, K. Pacak, D. Tokarev, J. Jelokova, D. Jezova and M. Rusnak, Neurochem. Res., 22, 995 (1997).

16. M.H. Mills, D.C.Finlay and P.R. Haddad, J. Chromatogr. B Biomed. Sci. Appl., 564, 93 (1991).

17. A.T. Wood and M.R. Hall, J. Chromatogr. B Biomed. Sci. Appl., 744, 221 (2000).

18. T. Yoshitake, J. Kehr, K. Todoroki, H. Nohta and M. Yamaguchi, Biomed. Chromatogr., 20, 267 (2006).

19. K.E. Hubbard, A. Wells, T.S. Owens, M. Tagen, C.H. Fraga and C.F. Stewart, Biomed. Chromatogr., 24, 626 (2010).

20. Martins and M.B.A. Gloria, Food Chem., 118, 529 (2010).

21. M.Y. Khuhawar and S.A. Majidano, Chromatographia, 73, 701 (2011).

22. G. Sarwar and H.G. Botting, J. Chromatogr. A, 615, 1 (1993).

23. K.-R. Kim, J.-H. Kim, C.-H. Oh and T.J. Mabry, J. Chromatogr. A, 605, 241 (1992).

24. A. Zinellu, S. Sotgia, E. Pisanu, B. Scanu, M. Sanna, M. Franca Usai, R. Chessa, L. Deiana and C. Carru, Anal. Bioanal. Chem., 398, 1973 (2010).

25. P.L. Chang, T.C. Chiu and H.T. Chang, Electrophoresis, 27, 1922 (2006).

26. C. Prata, P. Bonnafous, N. Fraysse, M. Treilhou, V. Poinsot and F. Couderc, Electrophoresis, 19, 4129 (2001).

27. V. Poinsot, P. Gavard, B. Feurer and F. Couderc, Electrophoresis, 31, 105 (2010)

28. D.A. Roman, A.S. Carretero, C.C. Blanco and A.F. Gutierrez, Biomed. Chromatogr., 18, 422 (2004).

29. A.M. EL-Brashy and S.M. Al-Ghannam, Pharm. World Sci., 17, 54 (1995).

30. P.J. Vandeberg and D.C. Johnson, Anal. Chem., 65, 2713 (1993).

31. C. Mayer, A. Frauer, T. Schalkhammer and F. Pittner, Anal. Biochem., 268, 110 (1999).

32. M. Perry, Q. Li and R.T. Kennedy, Anal. Chim. Acta, 653, 1 (2009).

33. M. Rubinstein, S. Chen-Kiang, S. Stein and S. Udenfriend, Anal. Biochem., 95, 117 (1979).

34. R. Soto-Otero, E. Mendez-Alvarez, J. Galan-valiente, E. Aguilar-veiga and G. Sierra-Marcuno, Biomed. Chromatogr., 8, 114 (1994).

35. L.E. Lavi, J.S. Holcenberg, D.E. Cole and J. Jolivet, J. Chromatogr. B, Biomed. Sci. Appl., 377, 155 (1986).

36. M.A. Sanz, G. Castillo and A. Hernandez, J. Chromatogr. A, 719, 195 (1996).

37. X. Kang, J. Xiao, X. Huang and Z. Gu, Clin. Chim. Acta, 366, 352 (2006).

38. D.J. Fekkes, J. Chromatogr. A, 682, 3 (1996).

39. P. Hernandez-Orte, M.J. Ibarz, J. Cacho and V. Ferreira, Chromatographia, 58, 29 (2003).

40. J. You, Y. Ming, Y. Shi, X. Zhao, Y. Suo, H. Wang, Y. Li and J. Sun, Talanta, 68, 448 (2005).

41. B. Dziechciarezyk, Arciwum Ochrony Srodowiska, 26, 153 (2000).

42. M.V. Baig, G.S. Kapse and S.A. Raju, Asian J. Chem., 13,185 (2001).

43. D. Satinsky, H. Sklenarova, J. Huclova and R. Karlicek, Il Farmaco, 58, 1057 (2003).

44. S. Cathum, V. Atamaniouk, L. Ananieva, C. Ladanowski and H. Whittaker, Can. J. Chem. Eng., 76, 680 (1998).

45. F.M.A. Rind, M.Y. Khuhawar and A.D. Rajper, J. Pharm. Biomed. Anal., 26, 331 (2001). 